\title{
Risco de contaminação do corante azul de tripano após primeira utilização
}

\author{
Risk of contamination of trypan blue dye after first use
}

\author{
João Baptista Nig'roSantiago Malta ${ }^{1}$ \\ Sérgio Felberg'2 \\ Maria Aparecida Soares Murça ${ }^{3}$ \\ Maurício Arruda Câmara Barros ${ }^{4}$ \\ Lycia Mara Genne Mimica ${ }^{5}$
}

\section{RESUMO}

Objetivos: Determinar o potencial risco de contaminação do frasco de azul de tripano (AT) depois de utilizado pela primeira vez e estocado em diferentes condições de temperatura e umidade, assim como identificar os possíveis fatores de contaminação, microrganismos mais freqüentemente envolvidos e simultaneamente avaliar as propriedades bacteriostáticas e bactericidas do corante. Métodos: Realizado estudo experimental, prospectivo, em que 30 frascos de AT foram divididos em três grupos (A: controle, B: armazenamento em geladeira e C: armazenamento em armário). O corante era aspirado e semeado em placas de ágar sangue e tubo de ágar Sabouraud. No grupo A o AT foi semeado apenas logo após a abertura dos frascos (tempo zero - T0), nos grupos B e C ocorreu semeadura nos T0, T1 (1 dia), T2 (2 dias), T7 (7 dias) e T10 (10 dias) após abertura dos frascos. No $10^{\circ}$ dia os frascos dos grupos B e C também foram submetidos a um raspado do lado interno do frasco após abertura. Concomitantemente foi realizado teste de ação inibitória do corante AT para estudo da atividade bacteriostática e bactericida. Resultados: As semeaduras realizadas no T0 não apresentaram contaminação. Entre os T1 e T10 mais o raspado houve apenas 1 frasco contaminado armazenado em geladeira. O microrganismo encontrado foi o Aspergillus niger. Foi comprovado que o corante não apresenta ação bactericida e bacteriostática para as bactérias testadas. Conclusões: Nas condições do estudo não houve contaminação dos frascos armazenados em armário e 1 frasco (10\%) armazenado em geladeira apresentou contaminação após abertura e uso inicial. A fonte de contaminação talvez seja o lado externo do produto. O AT não apresenta propriedades bactericidas e bacteriostáticas para as bactérias testadas e na concentração utilizada.

Descritores: Azul tripano/análise; Azul tripano/toxicidade; Aspergillus niger/isolamento \& purificação; Coloração e rotulagem; Tinturas; Catarata; Contaminação de medicamentos

\section{INTRODUÇÃO}

Corantes vitais são substâncias tintoriais utilizadas para corar tecidos vivos. Podem ser usados em oftalmologia com diversas finalidades, como exemplo os corantes rosa bengala ou fluoresceína utilizados na avaliação da superfície ocular, o azul de tripano (AT), tetrazol, indocianina verde e acridina laranja empregados na avaliação da viabilidade endotelial. Azul de metileno, AT e indocianina verde são corantes usados para tingir a cápsula anterior do cristalino e este último também pode ser utilizado para distinguir a membrana limitante interna da retina durante o ato operatório ${ }^{(1-3)}$. 
O AT é um corante vital, composto do sal de fórmula bruta:

$$
\mathrm{C}_{34} \mathrm{H}_{24} \mathrm{~N}_{6} \mathrm{Na}_{4} \mathrm{O}_{14} \mathrm{~S}_{4}
$$

de cor cinza azulado, solúvel em água e insolúvel em álcool. Foi inicialmente utilizado na prática oftalmológica, na concentração de $0,25 \%$, para identificação de danos nas células endoteliais, para assegurar a qualidade dos botões de córnea para ceratoplastia. As células endoteliais normais (viáveis) não são coradas, porém as células danificadas, cuja membrana é permeável ao corante, apresentam seu núcleo corado após 1 a 2 minutos do contato com o AT seguido da lavagem com solução salina balanceada ${ }^{(1,4)}$.

Com o advento da facoemulsificação e a introdução da capsulotomia curvilínea contínua (CCC) por Gimbel em 1990, o AT passou a ter fundamental utilidade na coloração da cápsula anterior do cristalino em diferentes situações ${ }^{(5)}$.

As principais indicações da utilização do AT na cirurgia da extração da catarata são: dificuldade na identificação da cápsula anterior do cristalino (catarata hipermadura), opacidades corneais (distrofias e degenerações corneais), treinamento de cirurgiões principiantes, catarata infantil (cápsula anterior muito elástica) e casos de dificuldade da identificação do "flap" capsular durante a $\mathrm{CCC}^{(6-10)}$.

Outra possível utilidade do AT é a coloração intra-estromal corneal para facilitar a realização da ceratoplastia lamelar profunda ${ }^{(11)}$.

As complicações associadas à utilização do AT são: tingimento de lentes intra-oculares, coloração inadvertida do humor vítreo, toxicidade ao endotélio corneal em altas concentrações e quando exposto por longo período e potencial carcinogênico $^{(12-15)}$.

Baseado nesta suposição, Yetik et al., determinaram, mediante um estudo, que a concentração de $0,0125 \%$ do corante (três diluições a partir da concentração usada inicialmente de $0,1 \%$ ) era capaz de corar satisfatoriamente a cápsula anterior do cristalino e conseqüentemente diminuir o suposto potencial carcinogênico ${ }^{(15)}$.

Atualmente, o corante AT está disponível comercialmente em nosso meio em frascos contendo $1,0 \mathrm{cc}$. A injeção de apenas 0,1 cc do corante na câmara anterior é suficiente para corar satisfatoriamente a cápsula anterior do cristalino ${ }^{(16-17)}$. Como o fabricante sugere ser o produto de uso único, cerca de $90 \%$ do produto é desprezado com o descarte do frasco após a primeira utilização (quantidade suficiente para mais nove injeções).

Com base nessas informações, este estudo teve como objetivo determinar o potencial risco de contaminação do frasco de azul de tripano depois de utilizado pela primeira vez e estocado em diferentes condições de temperatura e umidade, assim como identificar os possíveis fatores de contaminação, microrganismos mais freqüentemente envolvidos e simultaneamente avaliar as propriedades bacteriostáticas e bactericidas do corante.

\section{MÉTODOS}

Foi realizado estudo experimental, prospectivo, nos Departamentos de Microbiologia e de Oftalmologia da Santa Casa de
Misericórdia de São Paulo, no período de maio a setembro de 2004.

Foram utilizados 30 frascos do corante AT (azul de tripano ${ }^{\circledR}$, Ophthalmos Ind. e Com. de Produtos Farmacêuticos Ltda., São Paulo, Brasil, lote 060406), cedidos gratuitamente pelo fabricante e que tiveram seu uso aprovado para utilização através de um boletim de análise do produto realizado pelo programa de fármaco-vigilância da empresa.

Foram compostos três grupos contendo 10 frascos estéreis cada um:

A) Grupo controle.

B) Grupo em que o armazenamento do frasco após primeira utilização foi feito na geladeira do centro cirúrgico do Departamento de Oftalmologia da Santa Casa de São Paulo (temperatura de $+4^{\circ} \mathrm{C}$ ).

C) Grupo em que o armazenamento do frasco após primeira utilização foi feito no armário do vestiário do centro cirúrgico do Departamento de Oftalmologia da Santa Casa de São Paulo, com temperatura média de 20,66 $1,15^{\circ} \mathrm{C}$, variando entre $18,50 \mathrm{e} 23^{\circ} \mathrm{C}$, e umidade relativa de $63 \pm 1,67 \%$, variando entre 61 e $65 \%$, medidas através de termômetro e higrômetro respectivamente. (Barigo ${ }^{\circledR}, \mathrm{Ba}$ rometerfabrik, Villingen-Schwenningen, Alemanha).

$\mathrm{O}$ processo de semeadura foi realizado em condições de esterilidade, seguindo normas padronizadas, no Laboratório de Controle de Qualidade da empresa Probac ${ }^{\circledR}$ do Brasil Produtos Bacteriológicos Ltda., incluindo capela de fluxo laminar, utilização de avental e luvas estéreis pelos pesquisadores, além de máscaras e gorros apropriados.

Os frascos estéreis foram retirados do invólucro plástico, o lacre da tampa quebrado e 0,2 cc da solução aspirada através de uma seringa de insulina que transfixava a tampa de borracha do frasco, sendo o material colhido semeado em placas de ágar sangue e tubos de ágar Sabouraud.

No grupo A, o corante foi semeado apenas logo após a abertura dos frascos no tempo zero (T0); nos grupos B e C, foi semeado nos tempos: zero (T0), 1 dia (T1), 2 dias (T2), 7 dias (T7) e 10 dias (T10) após a abertura dos frascos. A partir do T1 foi utilizada gaze estéril e álcool a $70 \%$ para esterilização da tampa do frasco antes de nova coleta do corante.

No décimo dia os frascos dos grupos $\mathrm{B}$ e $\mathrm{C}$ foram submetidos, além da semeadura do corante, a um raspado do lado interno da parede do frasco logo após a sua abertura.

As placas de ágar sangue, após a semeadura do material, foram armazenadas na estufa à temperatura de $35 \pm 2^{\circ} \mathrm{C}$ do laboratório de Microbiologia do Serviço de Controle de Infecção Hospitalar da Santa Casa de São Paulo. Os tubos de ágar

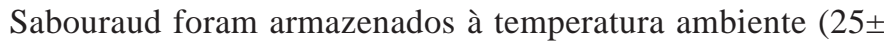
$2^{\circ} \mathrm{C}$ ) do laboratório.

Os meios de cultura foram examinados diariamente, por dois dias para ágar sangue e três semanas para ágar Sabouraud.

Além disso, foi realizado teste de ação inibitória do corante AT para estudo da atividade bacteriostática e bactericida. Foram selecionadas cepas padrões da coleção de cepas tipo americana (ATCC) de Pseudomonas aeruginosa (ATCC 
27853), Escherichia coli (ATCC 25922) e Staphylococcus aureus (ATCC 25923) e semeadas em ágar Müeller Hinton. Em cada placa semeada com as cepas, foram adicionados três discos estéreis (blank) embebidos com o corante AT (Figura 1). As placas foram armazenadas na estufa do laboratório de Microbiologia e avaliadas após 24 horas.

Este estudo foi avaliado pelo Comitê de Ética da Santa Casa de São Paulo, que autorizou sua realização.

Os autores não possuem interesse comercial nos produtos citados neste trabalho.

\section{RESULTADOS}

As 30 primeiras amostras do corante colhidas no T0 (10 de cada grupo) não apresentaram contaminação.

Das 100 amostras seguintes (50 do grupo B e 50 do grupo C) colhidas entre o T1 e T10, mais o raspado, uma amostra (1\%) apresentou contaminação.

$\mathrm{O}$ frasco contaminado estava armazenado na geladeira e a contaminação ocorreu no T1 do estudo. $\mathrm{O}$ agente encontrado foi o fungo Aspergillus niger.

Em relação ao teste de ação inibitória, após 24 horas de inoculação das cepas, foi observado que o corante não apresentou ação bactericida e bacteriostática para as bactérias testadas.

\section{DISCUSSÃO}

$\mathrm{Na}$ transição da técnica da cirurgia de catarata, da facectomia extracapsular para a facoemulsificação, diversas vantagens foram adquiridas como redução do tempo cirúrgico, anestesia tópica, recuperação ocular mais rápida com diminuição do processo inflamatório, alta precoce, entre outras. Po-

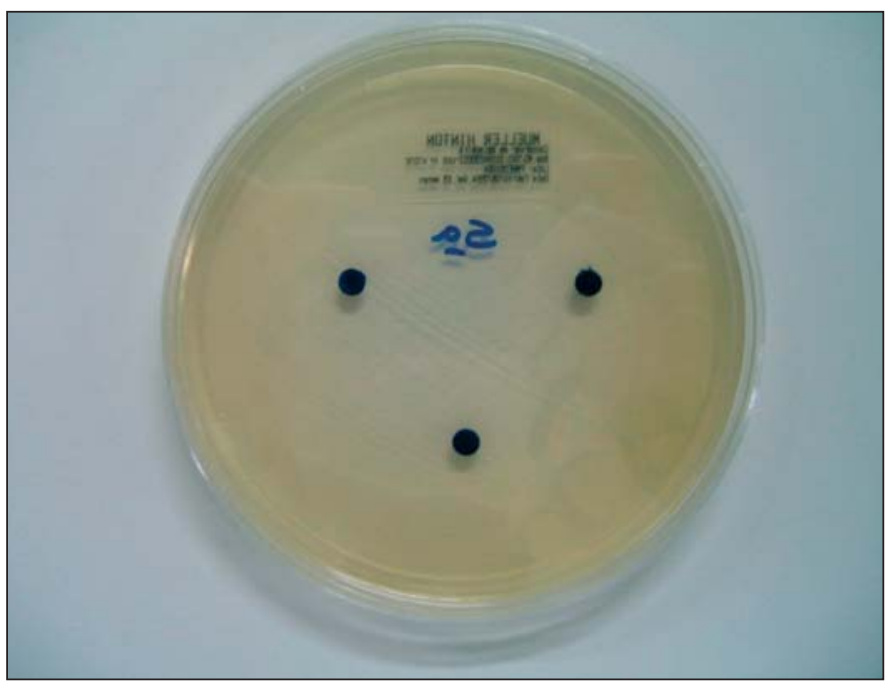

Figura 1. Placa de ágar Müeller Hinton semeada com cepas padrões e discos estéreis embebidos com azul de tripano. Fonte: Departamento de Microbiologia da Santa Casa de São Paulo, 2004 rém, uma desvantagem importante da nova técnica foi o aumento do custo do procedimento ${ }^{(18)}$.

Apesar das indústrias oftalmológicas, tanto na área farmacológica como na área cirúrgica, alertarem os médicos em relação à esterilidade de seus produtos e o modo adequado de utilização, diversos materiais de uso único cirúrgico, assim como fármacos, são reutilizados, com o objetivo de reduzir os custos dos procedimentos ${ }^{(19-21)}$.

$\mathrm{Na}$ facoemulsificação os principais materiais e substâncias reutilizadas de forma inadequada são: caneta do facoemulsificador, ponteira da caneta, luva de silicone da ponteira, mangueiras de infusão e/ou aspiração, assim como solução salina balanceada e eventualmente o corante azul de tripano ${ }^{(21-22)}$.

A reutilização inadvertida desses materiais propicia eventual contaminação por microrganismos, podendo aumentar o risco de infecções intra-oculares (endoftalmite) e a conseqüente perda da visão ${ }^{(19,22)}$. Nestes casos, os agentes de contaminação ambiental mais freqüentes são o Staphylococcus sp, Bacilos Gram positivos esporulados, Pseudomonas aeruginosa e fungos ${ }^{(23)}$.

No presente estudo, quando o AT foi utilizado como recomendado pelo fabricante, ou seja, uso único, não houve contaminação da amostra (30 amostras do T0).

Entre T1 e T10, das 100 amostras semeadas, ocorreu apenas uma contaminação, por fungo Aspergillus niger no T1 do frasco 9 armazenado em geladeira. No entanto, o mesmo frasco não apresentou contaminação nos períodos subseqüentes.

Este resultado sugere que, apesar da realização prévia da assepsia com álcool 70\% na tampa do frasco, a contaminação ocorreu por provável inoculação do agente no ato da coleta do material. Os álcoois desnaturam proteínas e dissolvem lipídios, podendo lesar a membrana celular de diversos agentes patogênicos. Apresentam ação sobre bactérias e vírus, agindo com menor intensidade sobre os fungos ${ }^{(24)}$.

Além disso, os fungos do gênero Aspergillus têm ampla distribuição geográfica, sendo contaminantes comuns em laboratórios e hospitais ${ }^{(25)}$.

$\mathrm{O}$ fato das amostras subseqüentes colhidas do frasco contaminado não apresentarem o mesmo agente pode ser explicado através de duas hipóteses:

1) O AT apresenta ação fungistática e fungicida. Para confirmar tal fato, seria necessário realizar teste de ação inibitória do corante com cepas do fungo Aspergillus niger.

2) O AT não favoreceu a multiplicação do Aspergillus, ou seja, o corante não é meio de cultura ideal para a multiplicação fúngica e/ou a temperatura de $+4^{\circ} \mathrm{C}$ da geladeira não é adequada para a multiplicação do agente.

Kawgakami et al., realizaram estudo em que cepas de Staphylococcus aureus e Pseudomonas aeruginosa foram inoculadas em frascos de fluoresceína. Após uma hora da inoculação, as culturas do colírio confirmaram a contaminação, porém observou-se que as culturas tornavam-se negativas com o decorrer do tempo. Esses resultados demonstram que mesmo após inoculação de bactérias em solução, com o passar do 
tempo os microrganismos não sobrevivem, pois provavelmente o meio em questão não era propicio para a multiplicação bacteriana $^{(26)}$.

Sugerimos testes semelhantes aos realizados por Kawakami, em diferentes temperaturas, com a utilização de cepas de fungos para confirmar a segunda hipótese.

Por outro lado, a ausência de contaminação bacteriana pode ser explicada através de três hipóteses:

1) Eficácia do álcool $70 \%$ durante assepsia. A assepsia com álcool $70 \%$ talvez tenha importante papel, evitando que o corante seja contaminado. Como comentado anteriormente, os álcoois apresentam ação sobre bactérias e vírus, lesando sua membrana celular ${ }^{(24)}$.

2) Ação bactericida e bacteriostática do AT. O teste de ação inibitória realizada com as cepas de Pseudomonas aeruginosa, Escherichia coli e Staphylococcus aureus demonstraram que o AT na concentração de $0,1 \%$ não apresenta ação bactericida e bacteriostática.

3) O AT não é meio de cultura propicio para a multiplicação bacteriana. Novamente sugerimos testes semelhantes aos realizados por Kawakami, com a utilização de cepas de bactérias para confirmar esta hipótese ${ }^{(26)}$.

Um dos objetivos do presente estudo foi o de verificar a possibilidade de contaminação de frascos de AT quando reutilizados, e não o de sugerir ou não nova utilização do corante após o primeiro uso. Isto significa que, embora apenas uma amostra dentre todas estudadas tenha apresentado contaminação, este resultado não deve servir de suporte para indicar a re-utilização do AT em seres humanos. Até que novos trabalhos sejam realizados, utilizando amostras maiores dos grupos estudados, sugerimos que as orientações do fabricante sejam seguidas e o produto não seja reaproveitado.

A endoftalmite fúngica causada pelo Aspergillus sp tem sido descrita na literatura nacional, demonstrando prognóstico reservado, difícil tratamento e muitas vezes conseqüências devastadoras ${ }^{(27-29)}$.

O presente estudo demonstrou que existe risco de contaminação do corante após abertura e que a prática de fracionar a utilização do corante pode colocar em risco o olho dos pacientes.

Sugerimos como alternativa para a otimização dos custos da cirurgia em relação ao AT a comercialização do frasco contendo quantidade reduzida do corante, já que, em média, apenas $10 \%$ do frasco é utilizado.

\section{CONCLUSÕES}

1) Nas condições do estudo, não houve contaminação dos frascos armazenados em armário após abertura e uso inicial.

2) Nas condições do estudo, 1 frasco (10\%) armazenado em geladeira apresentou contaminação após abertura e uso inicial.

3) A fonte de contaminação talvez seja o lado externo da tampa do frasco.
4) O AT não apresenta propriedades bactericidas e bacteriostáticas para as bactérias testadas, na concentração utilizada.

\section{ABSTRACT}

Purpose: To determine the potential risk of contamination of a trypan blue bottle (TB) after first use and after being stored under different temperature and humidity conditions, as well as to identify possible contamination factors, most frequently involved microorganisms and simultaneously evaluate bacteriostatic and bactericide properties of the dye. Methods: An experimental and prospective study was carried out, in which 30 TB bottles were divided into 3 groups (A: control, B: refrigerator storage and $\mathrm{C}$ : cabinet storage). The dye was suctioned and cultivated in agar blood plates and Sabouraud agar tube. In group A, TB was cultivated immediately after the opening of the bottles (temperature zero - T0), in groups B and $\mathrm{C}$ cultivation occurred in T0, T1 (1 day), T2 ( 2 days), T7 (7 days) and T10 (10 days) after the opening of the bottles. On the $10^{\text {th }}$ day, groups $\mathrm{B}$ and $\mathrm{C}$ bottles were also submitted to scraping of their inner walls after opening. Concurrently, the inhibitory action measurement test was conducted on the TB dye for the study of bacteriostatic and bactericidal activity. Results: Cultivation procedures conducted in $\mathrm{T} 0$ presented no contamination. Among T1 and T10, added to the scraping there was only one contaminated bottle stored in the refrigerator. The encountered microorganism was Aspergillus niger. It has been proven that the dye does not show bactericide and bacteriostatic properties against the bacteria which were tested. Conclusions: Under this study's conditions there was no contamination of the bottles stored in cabinets and 1 bottle $(10 \%)$ stored in the refrigerator showed contamination after opening and initial use. The source of contamination may possibly be the outer part of the product. TB does not show bactericidal and bacteriostatic properties against the tested bacteria and in the applied concentration.

Keywords: Trypan blue/analysis; Trypan blue/toxicity; Aspergillus niger/isolation \& purification; Staining and labeling; Dyes; Cataract; Drug contamination

\section{REFERÊNCIAS}

1. Almada AT. Coloração vital. In: Belfort Jr R, Kara José N. Córnea - clínica cirúrgica. Rio de Janeiro: Roca; 1997. p.129-33.

2. Centurion V, Caballero JC, Porto SM. Capsulorrexe com corantes [resumo]. Arq Bras Oftalmol. 2001;64(Supl 4):10.

3. Marques DMV, Marques FF, Osher RH. Three-step technique for staining the anterior lens capsule with indocyanine green or trypan blue. J Cataract Refract Surg. 2004;30(1):13-6.

4. Lima Filho AAS, Batistuzzo JAO. Formulário oftalmológico Ophthalmos. $6^{\underline{a}}$ ed. Rio de Janeiro: Cultura Médica; 2002. p.56.

5. Gimbel HV, Neuhann T. Development, advantages, and methods of continuous circular capsulorhexis technique. J Cataract Refract Surg. 1990;16(1):31-7.

6. Bhartiya P, Sharma N, Ray M, Sinha R, Vajpayee RB. Trypan blue assisted phacoemulsification in corneal opacities. Br J Ophthalmol. 2002;86(8):857-9. 
7. Dada T, Ray M, Bhartiya P, Vajpayee RB. Trypan-blue-assisted capsulorhexis for trainee phacoemulsification surgeons. J Cataract Refract Surg. 2002;28(4):575-6.

8. De Waard PW, Budo CJ, Melles GR. Trypan blue capsular staining to "find" theleading edge of a "lost" capsulorhexis. Am J Ophthalmol. 2002;134(2):271-2.

9. Jordão Jr A, Romão E. O uso do azul de trypan na cirurgia da catarata infantil [resumo]. Arq Bras Oftalmol. 2001;64(Supl 4):9.

10. Ursulino M. Capsulorrexe. In: Resende F. Cirurgia da catarata. $2^{\underline{a}}$ ed. Rio de Janeiro: Cultura Médica; 2002. p.211-21.

11. Balestrazzi E, Balestrazzi A, Mosca L, Balestrazzi A. Deep lamellar keratoplasty with trypan blue intrastromal staining. J Cataract Refract Surg. 2002;28(6): 929-31.

12. Chowdhury PK, Raj SM, Vasavada AR. Inadvertent staining of the vitreous with trypan blue. J Cataract Refract Surg. 2004;30(2):274-6.

13. Van Dooren BT, Beekhuis WH, Pels E. Biocompatibility of trypan blue with human corneal cells. Arch Ophthalmol. 2004;122(5):736-42.

14. Werner L, Apple DJ, Crema AS, Izak AM, Pandey SK, Trivedi RH, et al. Permanent blue discoloration of a hydrogel intraocular lens by intraoperative trypan blue. J Cataract Refract Surg. 2002;28(7):1279-86.

15. Yetik H, Devranoglu K, Ozkan S. Determining the lowest trypan blue concentration that satisfactorily stains the anterior capsule. J Cataract Refract Surg. 2002;28(8):988-91.

16. Melles GRJ, De Waard PWT, Pameyer JH, Beekhuis WH. Trypan blue capsule staining to visualize the capsulorhexis in cataract surgery. J Cataract Refract Surg. 1999;25(1):7-9.

17. Vieira E, Alonso RS, Souza Junior WF de, Azevedo MS, Lima VSWC. Capsulorrexe na catarata leitosa. Rev Bras Oftalmol. 2004;63(3):190-5.

18. Kara-José Júnior N, Avakian A, Lower LMT, Rocha AM, Cursino M, Alves MR. Facoemulsificação versus extração extracapsular manual do cristalino: análise de custos. Arq Bras Oftalmol. 2004;67(3):481-9.
19. Gutilla LD, Nishiwaki-Dantas MC, Freitas D, Coutinho, Nakasawa MSE. Prevenção no ambiente clínico-cirúrgico. In: De Souza LB, Freitas D, HoflingLima AL, Nishiwaki-Dantas MC. Manual de prevenção da infecção nos procedimentos oftalmológicos. São Paulo: Lemos; 2003. p.77-116.

20. Höfling-Lima AL, Lima AS, Batistoso JA, Kawamura D, Chalita MRC, Alves LS, et al. Contaminação de frascos de colírios de soro autólogo. Arq Bras Oftalmol. 2001;64(1):63-5.

21. Pereira IC, Alfonso E, Souza MACM, Song D, Muller D. Avaliação da contaminação de produtos oftalmológicos em uso. Arq Bras Oftalmol. 1992;55(1): 15-8.

22. Rao SK, Baskaran M, Kumar PJ, Vijaya L, Madhavan HN. Debris in phacoemulsification handsets. A potential cause of endophthalmitis after cataract surgery? Indian J Ophthalmol. 2004;52(1):80-1.

23. Trabulsi LR, Toledo MRF. Epidemiologia das infecções bacterianas. In: Trabulsi LR. Microbiologia. 2a ed. São Paulo: Atheneu; 1996. p.95-7.

24. Silva NP. Esterilização e desinfecção. In: Trabulsi LR. Microbiologia. $2^{\underline{a}}$ ed. São Paulo: Atheneu; 1996. p.99-102.

25. Gompertz OF, Ceballos BSO. Micoses oportunistas e outras micoses. In: Trabulsi LR. Microbiologia. 2a ed. São Paulo: Atheneu; 1996. p.99-102.

26. Kawakami LT, Prata Júnior JA, Reys JC, Guidugli T, Mello PAA. Avaliação da contaminação bacteriana na mistura de colírios de fluoresceína e drogas anestésicas. Arq Bras Oftalmol. 1995;58(3):186-8.

27. Leslie T, Aitken DA, Barrie T, Kirkness CM. Residual debris as a potential cause of postphacoemulsification endophthalmitis. Eye. 2003;17(4):506-12.

28. Machado DO, Curi ALL, Gonçalves R, Campos WR, Oréfice F. Endoftalmite bilateral por aspergillus em um paciente com leucemia linfocítica crônica [resumo]. Arq Bras Oftalmol. 2003;66(Supl 4):158.

29. Tzelikis PFM, Trindade FC. Endoftalmite fúngica endógena - Relato de caso [resumo]. Arq Bras Oftalmol. 2003;66(Supl 4):160.

\section{Simpósio da Associação Paranaense de Oftalmologia}

Congresso Sul-Brasileiro da SOBLEC II Congresso Sul-Brasileiro de Glaucoma

\section{2 a 24 de Junho de 2006}

IN FO RMAÇÕ ES: Tel.: (41) 3232-4031

E-mail: apoftalmo@onda.com.br

Home-page: www.simposioapo.com.br 